\title{
The use of ultrasound imaging for brachial plexus injury assessment following operative clavicle repair
}

\author{
Amanda H. Kumar, MD · James Kim, MD · Neda Sadeghi, MD • \\ Fraser J. Leversedge, MD • Claude T. Moorman III, MD • \\ Stuart A. Grant, MBChB
}

Received: 11 January 2018/Revised: 15 January 2018/Accepted: 15 January 2018/Published online: 30 January 2018

(C) Canadian Anesthesiologists' Society 2018

\section{To the Editor,}

Clavicle fractures and their treatment can be associated with neurovascular complications; the incidence of brachial plexus injury is $0-1.5 \%{ }^{1}$ Brachial plexopathy may be a result of direct or indirect injury such as traction, compression, or entrapment, given the proximity of the brachial plexus within $12 \mathrm{~mm}$ of the clavicle. ${ }^{2} \mathrm{We}$ describe a patient with brachial plexopathy after surgical repair of a clavicular fracture whose diagnosis was confirmed through bedside ultrasonography.

This otherwise healthy male presented after a fall with a mid-clavicle fracture. Fifteen days after injury, he underwent open reduction and internal fixation with a Rockwood clavicle pin under general anesthesia. In the postanesthesia care unit, the patient complained of new shooting pain in his arm, numbness of his hand and fingers, and diffuse motor palsy. Discussion with the surgical team revealed a difficult reduction intraoperatively that may have caused a traction injury.

One month postoperatively, he continued to have weakness and substantial muscle atrophy. The regional

\section{A. H. Kumar, MD $(\bowtie) \cdot$ S. A. Grant, MBChB}

Department of Anesthesiology, Duke University School of

Medicine, Durham, NC, USA

e-mail: amanda.kumar@duke.edu

\section{J. Kim, MD}

Department of Anesthesiology, University of Virginia, Charlottesville, VA, USA

N. Sadeghi, MD

Buena Vista Anesthesia Medical Group, Pasadena, CA, USA

F. J. Leversedge, MD · C. T. Moorman III , MD

Department of Orthopaedic Surgery, Duke University School of Medicine, Durham, NC, USA anesthesia division performed an ultrasonographic examination of the brachial plexus, which showed edema of the C5 and C6 nerves as they formed the upper trunk above the clavicle (Figure A). There was minimal edema of the middle and lower trunks. Evaluation confirmed continuity of the plexus without evidence of nerve rupture.

At three months postoperatively, the patient noted improvement in pain and motor function. Nerve conduction studies were consistent with a brachial panplexopathy with severe focused involvement of the upper and middle trunks. Repeat examination showed edema of the upper trunk above the clavicle that appeared improved compared to prior evaluation (Figure B). At 12 months postoperatively, he had substantial recovery. Ultrasonography revealed continued improvement in edema of the upper trunk, mirroring the patient's clinical course (Figure C).

Acute iatrogenic nerve injury after clavicular fracture repair predominantly involves the C5 and C6 nerves, upper trunk and lateral cord of the brachial plexus, and suprascapular nerve. While electro-diagnostic tests have been considered the gold standard in nerve injury assessment, they may not provide sufficient information until several weeks after the initial insult leading to delayed diagnosis. Ultrasound can provide reliable information, including dynamic determination of nerve continuity and presence of hematoma, foreign body, scar tissue, and neuromas. ${ }^{3}$ Furthermore, ultrasound can serve as a low-cost, quickly accessible adjunct to other diagnostic modalities.

Bedside ultrasonography has been used to diagnose complications of clavicular fracture, including subclavian artery pseudoaneurysm associated with brachial plexopathy. High-resolution ultrasound has been used to evaluate traumatic brachial plexus lesions and may be an additional tool in triaging patients as surgical or 


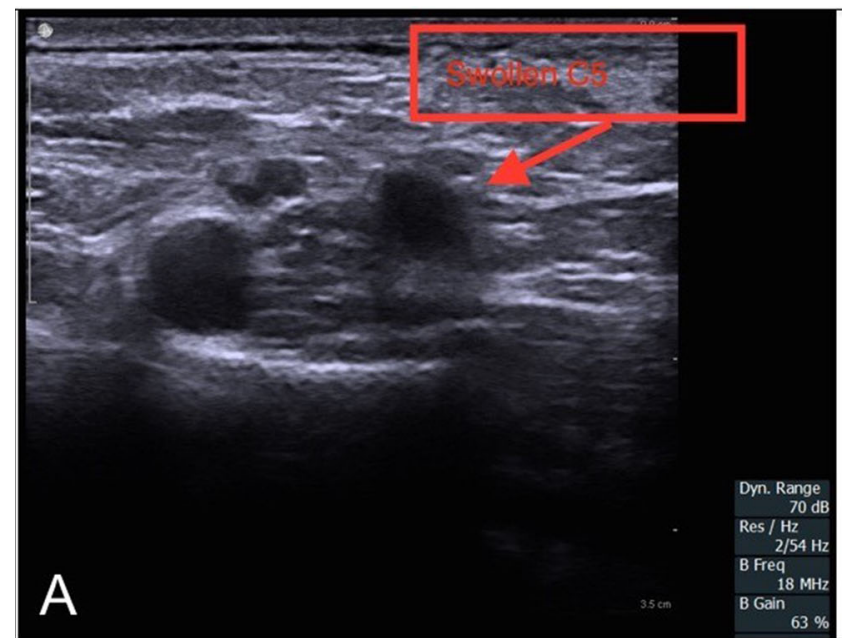

\begin{tabular}{|lc|}
\hline Motor Exam: 1 month post-operatively \\
\hline Shoulder abduction and external rotation & $1 / 5$ \\
\hline Elbow flexion & $1 / 5$ \\
\hline Elbow extension & $2 / 5$ \\
\hline Forearm supination & $1 / 5$ \\
\hline Forearm pronation & $4 / 5$ \\
\hline Wrist flexion and extension & $4 / 5$ \\
\hline Intrinsics & $4 / 5$ \\
\hline
\end{tabular}

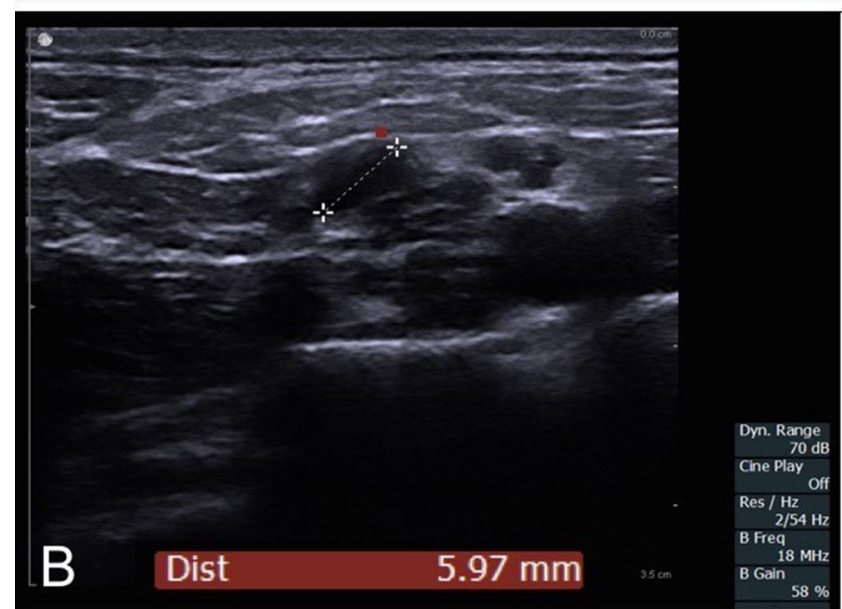

\section{Motor Exam: 3 months post-operatively}

Shoulder abduction and external rotation $\quad 3 / 5$

Elbow flexion

$2 / 5$

Elbow extension

$3 / 5$

Forearm supination

$2 / 5$

Forearm pronation

$4 / 5$

Wrist flexion and extension

$4 / 5$

Intrinsics

$5 / 5$

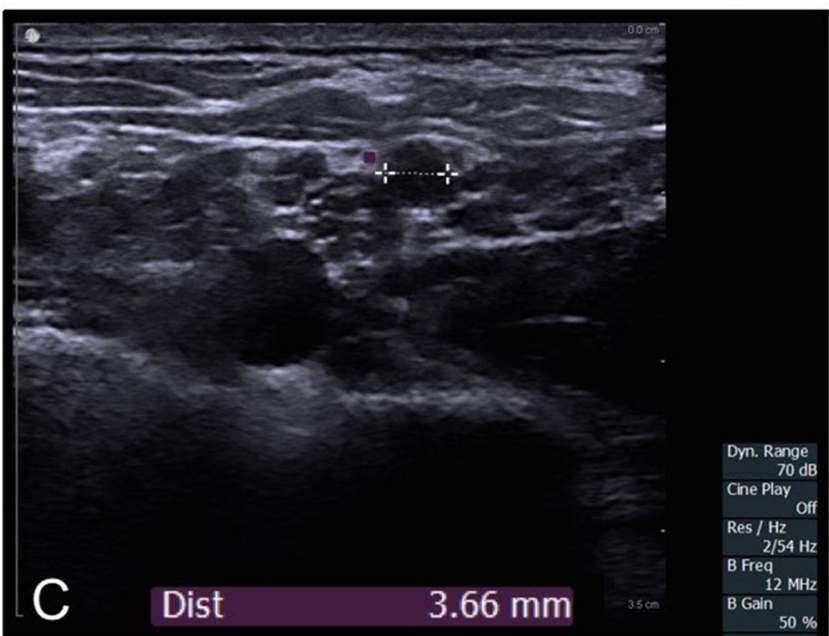

\section{Motor Exam: 12 months post-operatively}

\begin{tabular}{|lc|}
\hline Shoulder abduction and external rotation & $5-/ 5$ \\
\hline Elbow flexion & $4+/ 5$ \\
\hline Forearm supination & $5-/ 5$ \\
\hline Forearm pronation & $4 / 5$ \\
\hline Wrist flexion and extension & $5 / 5$ \\
\hline Intrinsics & $5 / 5$ \\
\hline
\end{tabular}

Figure (A) Ultrasound of brachial plexus at one month postoperatively showing edema and loss of detail of upper trunk. Motor examination at the time of evaluation is also shown. (B) Ultrasound of brachial plexus at three months postoperatively

showing enlarged upper trunk with the largest fascicle measuring $5.97 \mathrm{~mm}$. (C) Ultrasound of brachial plexus at 12 months postoperatively showing improvement in size of upper trunk, now measuring $3.66 \mathrm{~mm}$

non-surgical candidates. A retrospective review found that the mean time required for ultrasonographic examination of iatrogenic nerve injury was 15-20 min. ${ }^{4}$ High-resolution

ultrasound has been found to have $89 \%$ sensitivity and $95 \%$ specificity for the identification of transected nerves in a cadaver model. ${ }^{5}$ 
Anesthetic and analgesic management can be challenging in this population. Analgesic modalities include use of the superficial cervical plexus, interscalene, selective C5 nerve root, and supraclavicular nerve blockade. For patients undergoing operative repair, use of regional anesthesia is controversial. We propose that the ultrasound skills anesthesiologists possess are ideal tools to help diagnose and stratify the degree of nerve injury after clavicle surgery. We propose that patients receive a preoperative examination of their brachial plexus with ultrasound and documentation of images pre-surgery to allow comparison with post-surgical images should brachial plexus injury occur. Even if a lesion is diagnosed preoperatively, the clinician may be able to perform a nerve block at a site away from the lesioned area in at-risk patients. Preoperative ultrasound may also help identify patients at increased risk for postoperative nerve palsy.

Conflicts of interest None declared.
Editorial responsibility This submission was handled by Dr. Philip M. Jones, Associate Editor, Canadian Journal of Anesthesisa.

\section{References}

1. Wijdicks FG, Van der Meijden OA, Millett PJ, Verleisdonk EJ, Houwert RM. Systematic review of the complications of plate fixation of clavicle fractures. Arch Orthop Trauma Surg 2012; 132: 617-25.

2. Carofino BC, Brogan DM, Kircher $M F$, et al. Iatrogenic nerve injuries during shoulder surgery. J Bone Joint Surg Am 2013; 95 : 1667-74.

3. Cokluk C, Aydin K. Ultrasound examination in the surgical treatment for upper extremity peripheral nerve injuries: part I. Turkish Neurosurgery 2007; 17: 277-82.

4. Karabay N, Toros T, Ademoglu $Y$, Ada S. Ultrasonographic evaluation of the iatrogenic peripheral nerve injuries in upper extremity. Eur J Radiol 2010; 73: 234-40.

5. Cartwright MS, Chloros GD, Walker FO, Wiesler ER, Campbell $W W$. Diagnostic ultrasound for nerve transection. Muscle Nerve 2007; 35: 796-9. 